\title{
A behavioral analysis of whistleblowing at Japanese firms
}

Daisuke Asaoka (1) 1,2凶

This paper analyzes the background to whistleblowing-one of the key means by which a spate of corporate misdeeds have been revealed at established Japanese firms - by applying a framework of psychology and organizational behavior to people's decisions and judgments. The paper first analyzes the organizational aspects of whistleblowing, such as fear of retaliation within firms, and the psychological aspects, such as conflicts of interest that unconsciously favor sponsors. Despite such internal restraints, observed phenomena of whistleblowing paint a more nuanced picture of human psychology. Along with moral concerns, people have the desire to exhibit an appreciation of social trust and fairness, even when their actions are inconsistent with an economic calculus. Traditional Japanese firms are characterized by a collectivist culture featuring a meticulously crafted, closely knit internal order and lifetime employment. Information technology, however, has led to a more liquid flow of information on corporate misconduct, making it hard to conceal misdeeds that blur organizational boundaries and relativizing internal norms. These changes tip the psychological balance of people within firms and prompt firms to adapt. Changes in the corporate governance code, and a law requiring firms to introduce internal control systems, give whistleblowers the organizational protection which is key to according them psychological safety and encouraging constructive dissent. Advances in research from the behavioral perspective promise to deepen our understanding of Japanese corporate phenomena and behaviors.

\footnotetext{
${ }^{1}$ Meiji University, Tokyo, Japan. ${ }^{2}$ Kyoto University, Kyoto, Japan. ${ }^{\bowtie}$ email: asaoka@meiji.ac.jp
} 


\section{Introduction}

Context and definition of whistleblowing. Firms ensure that their business is conducted properly by putting in place internal control systems as required by corporate law and the stock exchange. Such systems typically involve a number of mechanisms and parties, ranging from monitoring by the board of directors and auditing by accountants to inspection by regulators and tax authorities. But another important element, often thought to exist outside of these formal mechanisms, is whistleblowing, which is actually an integral part of a firm's internal control system and, more generally, its corporate governance system. That corporate misdeeds, some hidden for decades, are being revealed by whistleblowers in blue-chip Japanese firms suggests a sea change in organizational behavior in modern Japan. A series of corporate misdeeds revealed by whistleblowers have prompted a number of corporate governance reforms, including the requirement that firms establish internal control systems to accommodate and protect whistleblowers, as articulated in the Japanese corporate governance code introduced in 2015 and amended in 2018 (TSE, 2018). Such behavior and institutional change stand in apparent contrast to the traditional Japanese corporate culture of conformity to organizational norms and avoidance of confrontational behavior. The purpose of this paper is to look at the role of whistleblowing in uncovering corporate wrongdoing at Japanese firms and to analyze its background from behavioral perspectives.

Whistleblowing, in the broad sense, is part of a firm's internal control system, yet it has distinct characteristics in terms of its avenues and social perception. While internal auditing is a major part of an internal control system involving regularly scheduled corporate assessments based on predetermined protocols, whistleblowing is an irregular action by insiders, lying outside of a firm's predictable routine even if positioned within the overall architecture of internal control. At first glance, whistleblowing might seem the exception rather than the rule as a form of internal control. However, a survey by the Japanese Consumer Affairs Agency (CAA) (2018b), the first of its kind, revealed that whistleblowers make up 58.8 percent of sources exposing corporate wrongdoing, surpassing 37.6 percent for internal audits. Hence, despite the apparent irregularities of whistleblowing, it is essential to examine its role as part of the internal control systems used to monitor firms. In 2019, the CAA introduced an accreditation system to ensure the quality of firms' internal control systems in accommodating and protecting whistleblowing (CAA, 2018c).

We define whistleblowing as acts by insiders within a firm to expose internal or external incidents which are illegal, inappropriate, or suspected to be so. Such acts can be categorized into four types, depending on the channel through which information flows: (a) an internal channel: Insiders expose incidents to an internal office responsible for handling such claims; (b) $a$ contracted channel: Insiders expose incidents to a designated outsider, typically a contracted law firm; (c) a government channel: Insiders expose incidents to the government, which has in place a hotline to accommodate such claims; and (d) a media channel: Insiders expose incidents not through a predetermined line, but through private avenues such as news organizations and social media. When we look at whistleblowing as part of an internal control system, only the (a) internal channel and (b) contracted channel, both of which a firm sets up in advance to deal with claims internally, are parts of the firm's official system, while the (c) government channel and (d) media channel are outside the firm's control in that claims flow through external paths and are dealt with primarily by third parties. What all of these have in common is that it is insiders who take the initiative to raise their voices; how their claims are handled depends on the nature of the claims and the avenues they take.
A "three-line" defense system is the standard means by which firms control misconduct throughout the organization. Wrongdoings, when detected, are corrected by passing through three layers: the business, administrative, and internal audit divisions. Incidents reported by whistleblowers are ones that these layers have failed to filter out. The definition above describes internal channels and contracted channels as parts of the internal system. Incidents reported by whistleblowers return to the internal system for processing. While government channels are outside a firm's purview, they are, at least, official and known beforehand to the firm. However, many news articles are generated from reports received through media channels, and firms cannot plan for these beyond maintaining a general preparedness for sudden media backlash. Information technology enables insiders, at least technically, to publicize inside information through text, sound and video, all of which place the firm at risk of exposure and media sensation.

Perspectives of the paper. While at least some whistleblowing channels are official parts of a firm's internal control system, the word itself conveys a certain uneasiness compared with such other functions of internal control as external and internal audits, auditing committees, and boards of directors. This is partly because the acts in question constitute misconduct, the uncovering of which may be followed by sensational news coverage, but also because whistleblowing departs from the common notion of Japanese corporate culture as a collectivist community (Hashimoto, 1991; Licht, 2018) where all ranks, from top management to newly hired graduates, share a destiny within a tightly bound, meticulous, longitudinal order (Nakane, 1967) and enjoy internal promotion under a lifetime employment system (Waldenberger, 2016). In fact, comparisons show that the collectivist cultures of Japan, Taiwan, South Korea, and China exalt the importance of loyalty and tolerate unfair but loyal behavior over the individualistic culture of the United States (Brody et al., 1998, 1999; Christie et al., 2003; Chiu, 2003). A survey taken of Japanese firms in 2003, before the 2006 enactment of the Whistleblower Protection Act, showed that people within firms did not look favorably upon whistleblowers (Wang et al., 2003).

To explain this discrepancy, it is useful to look at the concept of "loyalty and rebellion" coined by Maruyama (1992) in his search for consistent patterns in the thinking of Japanese people. This contrast shares some fundamental elements with recent experimental evidence from the U.S., which shows that people tend to make a tradeoff between loyalty and fairness when making whistleblowing decisions (Waytz et al., 2013; Dungan et al., 2015). The contrast between loyalty and rebellion, Maruyama claims, has been a traditional concept in Japanese communities from the country's feudal period through the modern age, in organizations as elsewhere. This claim does not, of course, presume that communities of samurai and corporate warriors are exactly the same. However, it provides us with an important insight: that this contradiction exists even in Japan's seemingly monolithic community, and that it persists to the degree that the Japanese regard it as a traditional concept. Illustrating the existence of such a contrast is the fact that conflicts within firms over corporate control are often described as family feud, even when no family members are involved. The familiarity of the term suggests that a firm is viewed as a family, and as such is not without conflicts among its members. Hence, it is reasonable to assume the existence in an organization of the contradictory factors of loyalty, characterized by a meticulously crafted order, and rebellion, a countervailing factor that may shake or even topple the hierarchy from within. Given this ambivalence, what is 
needed is a theoretical and experimental foundation for this kind of mentality within organizations.

It is worthwhile to note that the words loyalty and rebellion, and their contrast, require some care when applied to corporate whistleblowing. Obviously, one cannot argue that taking part in a cover-up of corporate misconduct is loyalty in its true sense. But neither can one claim that uncovering corporate misconduct constitutes rebellion, as subsequent corrections will improve the firm's credibility over the long term. If we make a distinction between the long-term and short-term effects of whistleblowing, we see that a short-term loss of credibility is followed by longterm internal improvement, and that a short-term gain through misconduct is followed by a long-term loss overall. Hence, in the context of uncovering corporate misconduct, we observe the paradox that short-term loyalty means long-term rebellion while short-term rebellion means long-term loyalty.

In present corporate settings, we set as a point of departure the fact that whistleblowing is the revelation of recent corporate misdeeds by sources within a firm, and that it outperforms internal audits for that function. Because we know relatively little about whistleblowing in comparison with other documented control mechanisms within firms, it is important that we consider its psychological and behavioral foundations and understand the process by which whistleblowers decide to take action. This paper therefore examines whistleblowing from the perspectives of cognitive science (psychology) and organizational behavior, and analyzes decisions and judgments by corporate whistleblowers whose actions are often based on psychologically contradictory thoughts and considerations.

The paper is organized as follows. Section "Case analysis" looks at some cases of whistleblowing in established Japanese firms. Section "Whistleblowing and organizations" analyzes whistleblowing and the elements hindering it, such as organizational response. Section "Psychological and organizational foundations of whistleblowing" discusses whistleblowing from certain psychological perspectives and relates it to institutional and organizational change. Section "Conclusion" concludes the paper.

\section{Case analysis}

Whistleblowing in established firms. Recent cases of Japanese corporate wrongdoing have involved fraudulent testing of car emissions and fuel economy, falsification of data for a public project to improve airport runway foundations, flawed manufacturing processes for blood products, fabrication of financial statements, fabrication of quality data for gum products, and a firm's assumption of private losses incurred at casinos by its top manager. In none of these cases did corporate insiders use official internal hotlines to report misconduct (CAA, 2018b). Insiders did not use the system available to them, fearing internal retaliation should they be identified and accorded no real legal protectiondespite being entitled to it under the Whistleblowers Protection Act of 2006, which bans detrimental treatment of whistleblowers.

Even when whistleblowers do dare to take action, they are often ignored. In 2015, only after a series of whistleblower reports, Toyo Tire disclosed that it had falsified data on its gum products and had gone so far as to list potential whistleblowers as an internal risk factor (MLIT, 2015). Toray, a Japanese textile and material manufacturer, disclosed in 2017 that a subsidiary had falsified data on its cord products, immediately after learning that such an allegation had been finally posted online (Toray Inspection Committee, 2017). Mitsubishi Material disclosed in 2017 that a subsidiary had falsified data on its automobile parts products - a claim which had been made by a whistleblower the previous year but ignored-and that four other subsidiaries had engaged in similar malpractice in manufacturing metal and gum products (Mitsubishi Material Inspection Committee, 2018). Also in 2017, Nissan revealed that a whistleblower had asserted the firm had persisted in having final product safety certified by nonqualified employees prior to shipping, despite the government's unearthing of the malpractice several months earlier in a random inspection and Nissan's having committed itself to correcting the practice and confirmed that it had done so (Nissan Inspection Committee, 2017).

The case of Olympus. Persistency of wrongdoing and fear of internal retaliation are revealed most conspicuously in the case of Olympus, the Japanese camera and endoscope manufacturer. Here we see that fear of retaliation is felt not only by employees, but even by top managers. Woodford (2012) describes an experience he had in 2011, immediately after becoming the first non-Japanese CEO of the firm. Woodford had uncovered the firm's long-time practice of hiding its losses by fabricating financial statements through the use of complex financial transactions involving entities established in overseas tax havens. He describes his psychological conflicts and fears when his whistleblowing led to his immediate dismissal as CEO by the board of directors, sudden alienation within the organization which formerly had celebrated him, threats to his own safety, burdens on his family, and even potential lawsuits against him by the firm's shareholders. For the three former directors who ordered the misdeeds, the incident resulted in guilty sentences handed down by the Tokyo District Court under the Financial Instruments and Exchange Act, which became final in 2013. A parallel civil judgment by the Tokyo High Court in 2019 ordered the three to pay damages of 59.4 billion yen (about $\$ 540$ million). Woodford did not return to the firm, which later paid him 10 million pounds in a settlement reached in 2012 .

A top manager had become a whistleblower, embarking on his own research after reading media reports apparently based on inside information. His sudden dismissal by the board of directors pushed the Japanese government to provide better protection for whistleblowers. It set up a council to amend the Whistleblower Protection Act to include provisions obliging large firms to establish internal protection systems for whistleblowers and expand the scope of those accorded protection; notably, these would include not only employees but executives. The amendment passed the Diet in 2020. More broadly, the incident pushed the country toward corporate governance reform, which crystalized in the corporate governance code introduced in 2015 and amended in 2018. Olympus, battered by the revelations, had to resort to outside resources: In 2012, Sony, interested in the firm's endoscope technology, became Olympus's top shareholder with an 11.5 percent holding and a seat on the board (Olympus Corporation and Sony Corporation, 2012). In 2019, however, it sold its entire holdings following a call by an activist fund to unload its non-core assets. In the same year, another activist fund, ValueAct, had three seats on the board at Olympus (Olympus Corporation, 2019).

The Woodford case had a forerunner at Olympus, however. In 2007, a sales and marketing veteran with over 20 years at the firm, Masaharu Hamada, alleged to the internal compliance office that his boss had been poaching from a client employees who were knowledgeable about the client's internal secrets. He expected the office to stop the practice, but instead it leaked his identity as the whistleblower to his boss. Hamada was immediately relocated to a section in which he had no expertise, required to write irrelevant business reports in solitude, and then relocated twice more as if he were a freshman employee. He sued the firm, winning his case at the Supreme Court in 2012, and was allowed back to work in a position suited to his experience. But despite the court's ruling, 
Olympus again tried to relocate him, this time to a subsidiary. Hamada sued the firm again in 2013, resulting in a settlement in the lower court in 2016 that finally saw him returned to a relevant office (Tokyo District Court, 2016). He had waged a 9-year court battle. The Woodford case of 2011 occurred in the middle of all this, triggered by a news report apparently based on insider information.

\section{Whistleblowing and organizations}

Response within the organization. The Olympus case reveals not only that firms harbor misconduct and cover it up, but also that they are willing to fight back against whistleblowers, even when these are top managers or company veterans. Fears of retaliation are real, therefore, and action, by an employee or other person with knowledge of the situation, is necessary in order for misconduct to be uncovered and corrected. Without such intervention, corporate misdeeds will remain under cover. Indeed, Japanese people rarely report misconduct or cover-ups started by their predecessors because once a wrongdoing has begun, any attempt to correct it means a betrayal of the organization (Kubori, 2018). People are forced to be "loyal" in organizational settings.

An act of whistleblowing should be seen per se as the success of a firm's internal controls, as it indicates that internal systems are functioning properly, but the first thing a firm does upon receiving such a report is to search for the "perpetrator" (Kubori, 2019). In reality, employees who turned whistleblower have often been reassigned or dismissed (CAA, 2018a). Hence, the protection of whistleblowers is essential, not as a formality but in substance, in order to reduce the fear of internal retaliation that gets in the way of deciding whether to report or remain silent.

Errors in whistleblowing. Despite the importance of protecting whistleblowers, there are times when employees perceive incidents as misconduct when actually they are not. In such cases, reporting would cause the firm to suffer undeserved defamation and loss of reputation. If a whistleblower picks up on an incident that the three layers of internal defense have failed to filter out, the failure of these official layers may indicate that the whistleblower is actually mistaken. Sometimes it is hard to draw a clear line between acts which are acceptable and those which constitute wrongdoing. To do so involves a certain degree of judgment. This uncertainty may be greater if the allegation involves unwritten rules and ethics. In practice, legal and compliance risks are often explicitly recognized and discussed as part of managerial decision-making in the regular course of business, with the advice and assistance of legal counsel.

Two types of errors thus arise from this uncertainty: type I, the overlooking of misconduct which really is misconduct (failure to report true misconduct), and type II, the reporting of objectively just conduct as misconduct (reporting false misconduct). In the former situation, people fail to take action even when observing true misconduct because of psychological or organizational restraints (group norms, pressure to conform, or fear of retaliation). In the latter situation, people do take action but are mistaken in doing so. This occurs because some cases involve an element of judgment which depends on one's subjective views. Table 1 summarizes combinations of decisions and their consequences in regard to acts and omissions concerning true and untrue misconduct, including the two types of errors.

The type I error, the covering up of true misconduct, arises out of psychological biases and the organizational fear of a search for the perpetrator. People witness misconduct, but stop short of taking action. Such omissions create a culture which accommodates omissions, and may even lead to decades of wrongdoing. This was actually observed among Japanese firms, as in Nissan's nearly four

\section{Table 1 Types of errors and consequences.}

\begin{tabular}{cll} 
Allegation & $\begin{array}{l}\text { Decision } \\
\text { Report }\end{array}$ & Failure to report \\
\hline True & Report true misconduct & $\begin{array}{l}\text { Failure to report true } \\
\text { misconduct } \\
\text { (Type I error) }\end{array}$ \\
Firm & Justified loss of reputation and "search & $\begin{array}{l}\text { Unjustified success of cover- } \\
\text { up }\end{array}$ \\
Individual & for perpetrator" & Possible liability \\
Intrue & $\begin{array}{l}\text { Report untrue misconduct } \\
\text { (Type II error) }\end{array}$ & $\begin{array}{l}\text { Failure to report untrue } \\
\text { misconduct }\end{array}$ \\
Firm & Unjustified loss of reputation & - \\
Individual & Possible liability & - \\
\hline
\end{tabular}

decades of misconduct in product safety inspection (Nissan Inspection Committee, 2017) and Kobe Steel's five decades in data falsification (Kobe Steel Inspection Committee, 2018).

The type II error, the unjustified reporting of objectively untrue misconduct, arises out of human differences in perception and judgment which are examined after the whistleblowing has taken place. Presented with the possibility that a whistleblower was mistaken, none of the four channels normally used-internal, contracted, government, or media-makes any immediate response. If a whistleblower has employed an outside channel without cause, the firm may even punish the whistleblower for leaking inside information or defamation. As we see below, the degree of error allowed for mistaken reports relates to the willingness of individuals to come forward.

From the viewpoint of an individual who reports misconduct, it is only these two types of errors-failure to report true misconduct, and reporting false misconduct-for which they should be held liable, if for anything at all. There is a tradeoff in that better protection of whistleblowers decreases the likelihood of the type I error while increasing that of the type II error, and vice versa. The central issue for whistleblowers, however, is not the tradeoff between the two types of errors, but that they may be held liable even for reporting true misconduct. (The remaining quadrant, failure to report untrue misconduct, indicates nothing occurring because no problem exists.) While a whistleblower's justified reports of true misconduct lead to (justified) punishment and loss of reputation for firms, such a whistleblower may also face de facto punishments such as dismissal, relocation, ostracism by peers, and disfavor by the boss-despite the legal protections given by the Whistleblower Protection Act. This can be called "implicit punishment," as shown in Table 1.

Obviously, such undeserved treatment will cause individuals to shrink from reporting, and thus indirectly affects the tradeoff by increasing the type I error of failing to report true misconduct. Here, the tradeoff between the type I error (failure to report true misconduct) and the type II error (reporting untrue misconduct) is distorted by the (unjustified) implicit punishment for reporting true misconduct. The relative scale of true misconduct revealed by whistleblowers compared to untrue misconduct mistakenly reported by whistleblowers suggests that, even aside from the effects of sensational media coverage, individuals require a grave cause to take an action which overrides the possibility of their being unfairly treated, punished, or even threatened.

Conflicts of interest. Individuals pressured by organizational dynamics tend not to report the misdeeds they witness. From the perspective of organizational psychology, they have reason for this. It is generally known that a group environment allows a diffusion of responsibility (Darley and Latané, 1968) in the face of misconduct and causes indifference among bystanders (Latané and Darley, 1969). More importantly, people find more justification for committing wrongdoing, or overlooking it, when it benefits others rather than themselves. A similar excuse is used 
for de facto collusion, where people who are supposed to monitor each other give each other the benefits of misconduct and excuses while knowing they will ultimately benefit themselves (Gino et al., 2013). Similarly, people are known to adjust their fairness criteria to accord with their position, regarding criteria favorable to themselves as fair (Thompson and Loewenstein, 1992). These are important insights when seen from the perspective of a corporate setting: Often, corporate employees do not gain directly from committing misconduct or overlooking it, but do obtain indirect benefits when the act helps to lift their firm's apparent earnings. This "for-the-firm" mentality justifies and even amplifies misconduct by giving individuals a moral excuse, which is a key negative aspect of corporate loyalty. Mazar and Aggarwal (2011) show that a collectivist culture is more prone to bribery in international business than an individualistic one because of differences in perceived responsibility for one's actions.

This tendency is amplified by a mentality which prizes obedience to authority (Milgram, 1963; Burger, 2009). In an experimental exercise on whistleblowing, participants were given the option of obeying or whistleblowing when posed with an unethical request by the investigator. A majority chose to obey the request, while another set of participants who were given the same request without the presence of the investigator, and therefore not under psychological pressure, had exactly the opposite reaction (Bocchiaro et al., 2012). Harvey et al. (2010) further found that if people were asked to evaluate a group of paintings, and were informed beforehand of the existence of a sponsor who would pay them for doing so, they unconsciously gave higher evaluations to paintings that had their sponsor's logo in the corner. In the experiment by Bocchiaro et al., participants who were not given a pecuniary incentive would still obey a person with apparent authority. The finding by Harvey et al. suggests that obedience bias is amplified in corporate settings, where pecuniary incentives are common. Firms offer their employees jobs and compensation, making them their obvious sponsors. Within firms, therefore, norms are not only established by persons having authority within a group, given the corporate hierarchy, but also by sponsors, given the pecuniary reward relationship. And since one's perception of one's sponsor tends, if unconsciously, toward the favorable, to proactively uncover and overturn fraudulent acts within an organization is a difficult matter.

Insiders who notice wrongdoing within their organization find themselves bound by a conflict of interest, as they are drawn to both favor and harm their sponsors. Moore et al. (2010) showed that when conflicts of interest exist, people's decisions are more biased than they believe, even when they are aware of their bias. The tightly knit, collectivist culture of Japanese firms adds an extra element to the mix, in that the denial of any act within an organization can mean self-denial: Acts committed by people in the same organization create further psychological obstacles to objection. Apart from the effect of pecuniary reward relationships, people are obviously reluctant to (essentially) deny themselves. Confronting misconduct is even more painful when the sponsor in authority is perceived to be part of oneself as well as fraudulent. This sense of oneness may even act as a motivation to cooperate in covering up misconduct, or at least to choose to do nothing, in order to protect one's firm and oneself.

\section{Psychological and organizational foundations of whistleblowing}

Psychological ambivalence. As seen in the previous section, people have a tendency to overlook misconduct and to conform to the thoughts and actions of others in their organization. Individuals pressured by organizational dynamics and placed in psychological conflict tend not to report the misdeeds they witness, and to conform to the thoughts and actions of others in their organization. But the fact that whistleblowing still takes place despite biases and pressure indicates that human psychology is more nuanced and contradictory than it may first appear, and that different motives cause people to overcome these hurdles.

Psychological experiments have illuminated these nuances, showing that people base choices not solely on simple cost-benefit comparisons, but on social trust and fairness, even when to do so may be detrimental in terms of economic rationale (Guth et al., 1982). Similarly, people tend to punish wrongdoing by others from the viewpoint of social trust and fairness, even when they know that doing so will incur economic loss on their side (Fehr and Fischbacher, 2004). On the contrary, it is shown that there is little or no monetary incentive to reveal fraud (Dyck et al., 2010).

Wrongdoers, too, have been shown to limit their misconduct, keeping it below the ultimate degree possible even when sure they will not be found out. They stop short of their profit maximizing point, presumably out of a desire to maintain at least a somewhat honest self-image (Mazar and Ariely, 2006). Decisions and judgments are often made ambivalently, and, reflecting this, behavior within an organization carries the contradictory factors of loyalty and rebellion-not unusual given the psychological nuances and ambivalence of people in general. It is this ambivalence, and, moreover, the underlying sense of social trust and fairness, which form a psychological foundation for whistleblowing, pushing people to think beyond the economic calculus that would otherwise let them cover up or overlook misconduct. Indeed, Dungan et al. (2019) show that moral concerns consistently predict real-world whistleblowing decisions above and beyond other organizational factors.

This sense of trust and fairness as well as moral concerns are also affected by our environment. People commit fewer misdeeds when aware that others are watching (Ariely, 2012). But this is also the case when they only have the impression of being watched, as when surrounded by pictures of eyes (Bateson et al., 2006). Even when not being watched, people limit their misconduct when asked to obey an actually nonexistent code of ethics (Mazar and Ariely, 2006). People are consistently ethical in an organizational climate that values justice, while individual characteristics do not necessarily produce predictable tendencies (Vadera et al., 2009). People who felt their organization had educated them about their rights as whistleblowers, and who perceived their organization as fair, were more likely to use internal channels (Dungan et al., 2019). The existence of an internal control system thus affects people not only by presenting a threat of punishment, but also by reminding them of the sense of ethics that underlies that system.

Moreover, the prevalence of social networks not only lowers the psychological bars and costs for individuals revealing misconduct, but introduces a sense of being seen, because anyone in a group can be a whistleblower. The ease of use of such technology increases the frequency with which people learn of actual cases and repercussions of whistleblowing outside their group. This may further lower the bar for potential whistleblowers through availability bias (Tversky and Kahneman, 1973), by which people believe an event is more likely to occur than it is in reality when informed of similar events that have actually occurred. If people learn of misconduct revealed by a whistleblower through a news outlet or social media, they easily remember other recent cases and perceive whistleblowing to be more common than it actually is, thus partly offsetting any organizational and psychological restraints. The greater availability of information outside an organization also mitigates the bias wherein people justify committing fraud by thinking that other people do it as well, even when that is not the case (Tenbrunsel, 1998).

While it is an organization's informal culture that sets norms for what is and is not allowed (Tenbrunsel et al., 2003), the unprecedented availability of avenues for whistleblowing blurs 
organizational boundaries and affects the contour of firms characterized by a meticulous, closely knit order by making it harder to keep knowledge of wrongdoing inside the company. This influences the psychological balance of people subjected to contradictory factors, possibly even shifting their normative sense through knowledge of misdeeds and their consequences. Such changes also create a sense of tension and reputational risk that pushes firms to take precautions.

In an environment where misconduct is overlooked or covered up by people operating under organizational pressures and psychological biases, there is also a countervailing motive: the psychological reward gained by maintaining social trust and fairness despite the possibility of incurring apparent economic loss. People may conform to organizational norms through mutual reinforcement and attempts to justify misconduct, but when actual corporate misconduct is revealed by a whistleblower, the validity of this justification is undermined. The norms are relativized within a more general normative sense which is shared with people outside the firm and provides new clues for what constitutes a norm.

Institutional change. It is not solely an individual's sense of trust and fairness that tips the balance toward whistleblowing, as whistleblowers are also motivated by the degree to which conditions suggest they will be effective (Dozier and Miceli, 1985). Overlooking wrongdoing is associated with lower perceived organizational support and lower perceived justice of reporting channels (Miceli et al., 2012). Psychological motivations, while necessary for an individual to take action, are insufficient on their own. Institutional arrangements are needed as a complement, particularly in regard to the protection of whistleblowers, and, more broadly, the better monitoring of firms. This is especially true for firms which see whistleblowing as a form of rebellion within the organizational dynamic, and would answer it with implicit punishment were it not for institutional protections.

In 2018 the Japanese government amended the Code of Criminal Procedure to introduce a plea deal system. The system was applied to the whistleblowers in a case at Nissan, just 5 months after its introduction, in regard to alleged irregularities concerning the disclosure of compensation and the private use of corporate funds. This was followed by the resignation of Nissan's CEO and a subsequent Japanese CEO over similar irregularities involving compensation disclosure (SESC, 2019). By rewarding those who report true misconduct, not through pecuniary payment but by reducing the legal penalty, the system helps to elicit testimony that contributes to discovery of the truth. Japanese law had traditionally opposed such a system out of concern that it might encourage false accusations (equivalent to the type II error of reporting untrue misconduct), but the amendment indicated that this concern was less urgent than the possibility that without compensation, implicit punishment might deter the reporting of true misconduct (equivalent to a type I error). This system clearly has a similar effect on the tradeoff as it increases the possibility that people will report true misconduct by reducing their loss in the form of the legal penalties which could otherwise have been justified.

In the same year, Japan amended the corporate governance code for listed firms. The code was originally introduced in 2015 as a stock exchange rule of the comply-or-explain type (TSE, 2018), which requires firms to disclose their reasons when not complying with a rule, and was modeled after similar codes of the United Kingdom (Financial Reporting Council, 2018) and the G20 and OECD (G20 and OECD, 2015). The amended code requires firms to accommodate and protect whistleblowers through an internal control system including a prohibition on unfair treatment for whistleblowers (Principle 2.5 and
Supplementary Principle 2.5.1). In 2019 this was accompanied by the Consumer Affairs Agency's accreditation of internal control systems to accommodate and protect whistleblowers, and in 2020 by amendment of the Whistleblower Protection Act to provide greater protection to whistleblowers, such as by exempting them from damages related to whistleblowing (\$7) and ensuring confidentiality on the side of firms $(\$ 12)$.

The code affects the internal culture of Japanese firms by further requiring them to establish the role of independent directors in improving managerial transparency by injecting an outsider's viewpoint. Under Japanese corporate law (the Companies Act), the traditional means of introducing an outsider's viewpoint into the monitoring of firms had been through "statutory auditors" elected at the annual shareholder meeting. Giving greater power to statutory auditors was not the answer to the urgent calls for more transparency among Japanese firms, as statutory auditors, especially those promoted internally, are typically regarded as people who have lost the contest for promotion to senior management. They also are apt to show leniency toward the winners (who, in essence, have given them a consolation prize for their years of faithful service). Rather, the code focused on the board, requiring at least two members to be independent (Principle 4.8). As of 2018, 99.3 percent of the firms listed in Section 1 (the largest section) of the Tokyo Stock Exchange were in compliance with the code; on average these had 2.5 such directors out of an average of 9.2 directors on the board (TSE, 2019). The change was accompanied by an amendment to the Companies Act in 2019 that obliges listed firms, without exception, to have at least one independent director (\$327-2).

The code is also noteworthy for promoting a diversity of perspectives and values (Principle 2.4). Whistleblowing is a divergent practice, and those who practice it can be ostracized without appropriate protection. The observed phenomena of whistleblowing, however, may already indicate increased diversity within an organization. If long-practiced misconduct is discovered by a "stranger" in a traditionally homogenous, collectivist organization, promoting diversity may have the effect of relativizing such a corporate culture. It has been suggested that a devil's advocate be installed in the organization to promote this end (Nemeth, 2018), rather than adhering to the traditional Japanese practice of building consensus before each formal meeting. Diversity is key to early detection as well, given that misconduct tends to be contagious, with people most liable to commit wrongdoing when observing it being committed by someone with whom they feel a shared identity (Gino et al., 2009). Whistleblowing, or its recognition as part of an internal control system, serves to alleviate internal pressure to conform to the group. Notably, Dungan et al. (2015) explore how prioritizing constructive dissent can encourage whistleblowing while strengthening group cohesion, and point out that overcoming a certain level of conflict can actually strengthen team cohesiveness.

The institutional changes embodied by the introduction of the plea deal system and the corporate governance code, as well as the amendments to laws, emphasized the protection of whistleblowers and the need for an outsider's view. These changes affect the decisions, judgments and even perceived norms of people operating within an organization. Because these institutions protect internal whistleblowers as part of a formal internal control system, top management are put on notice that they are being watched not only from outside the firm, but also from inside it. This blurring of internal and external boundaries encourages the introduction of outside viewpoints and brings insiders closer to the outside world. Such changes alleviate the organizational hurdles faced by whistleblowers by relativizing the traditional notion of closely knit, collectivist organizations and affecting the norms formed within them. 


\section{Conclusion}

The purpose of this paper was to analyze the background to whistleblowing, a key means of uncovering corporate misconduct in established Japanese firms, by applying a framework of psychology and organizational behavior to human judgments and decisions that are often ambivalent and self-contradictory.

The paper analyzed corporate misconduct from organizational perspectives such as the fear of retaliation and psychological viewpoints such as conflicts of interest and obedience to authority. On top of that analysis, it showed that human psychology has contradictory factors which cause people to conform in order to cover up misconduct and also to expose it. It is a human tendency to acquire norms and conform to them, and also to turn a blind eye to misconduct, often through self-justification. But people also have the desire to maintain an honest self-image, and to display social trust and fairness as well as moral concerns - even if doing so goes against economic rationale.

Traditional Japanese firms are often characterized as coherent, homogenous communities with a meticulously crafted, closely knit internal order, which hire new graduates from college and have lifetime employment and internal promotion systems. A more liquid labor market would remove one of these restraints, as whistleblowers would find it less difficult to leave their firms; but the market remains stubbornly illiquid. On the other hand, even assuming a more liquid labor market, developments in information technology will create a more liquid flow of information on corporate misconduct. With cases of revealed misconduct more available, internal norms will become relativized, making it harder to conceal wrongdoing within firms based on (unjustified) loyalty. These changes, along with requirements for greater transparency and diversity, may affect the psychological balance of employees and prompt firms to adapt. Also serving this purpose are systems aimed at enhancing protection for whistleblowers, such as plea deals, the corporate governance code and the amendment to the Whistleblowers Protection Act requiring firms to introduce internal control systems to accommodate and protect those who bring misdeeds to light. These institutional changes are helping to alleviate the organizational pressure on whistleblowers, a central factor in substantiating corporate governance reform involving corporate misconduct, at the same time as they transform the traditional corporate culture.

This paper is characterized by a behavioral approach which presents certain limitations. The results of experiments conducted outside Japan may not directly apply to Japanese people, and research in this field is still fledgling. In an environment in which firms and people move across borders, arguments for unique, Japan-specific elements might be less than valid, at least concerning issues of internal controls that primarily look at the legality of corporate conduct; but one must also recognize that a homogenous, collectivist culture, while intangible, is a persistent characteristic of Japanese firms, and one which may well affect the design and management of internal control architecture. Given our vast store of insights into the psychological foundations of human behavior within organizations, an additional insight into Japan-specific elements would be helpful in promoting our understanding of corporate misconduct.

Future research might take a number of directions. One avenue is empirical research on the behavior and psychology of Japanese people. Given the cultural differences in the degree of obedience and conformity and the permitted level of dissent in a group, an inquiry in this direction would lead to richer insights into this field and provide an interesting comparison to the existing research. Another possibility, which might have general relevance rather than comparative, is research on compensation. As shown in the paper, people are known to find psychological reward in maintaining fairness, even if doing so incurs economic loss and act accordingly.
One of the highlights of the ongoing corporate governance reform is management compensation, but its main focus is on pecuniary compensation, which, in its promotion of more stock-based compensation rather than cash salary and bonuses, aims for a better alignment with shareholders. From the viewpoint of this paper, however, it seems that non-pecuniary compensation such as social recognition and reputation matters. As this also relates to the illiquidity of the Japanese labor market and the collectivist nature of its firms, psychological rewards, such as recognition and honor within the organization, seem important in defining the directions of Japanese behavior, including the prevention of misconduct. Advances in behavioral research into corporate misconduct suggest an interesting future agenda that promises to deepen our understanding of Japan's people and organizations.

Received: 22 April 2020; Accepted: 25 August 2020; Published online: 16 September 2020

\section{References}

Ariely D (2012) The honest truth about dishonesty: how we lie to everyone-especially ourselves. HarperCollins, New York

Bateson M, Nettle D, Roberts G (2006) Cues of being watched enhance cooperation in a real-world setting. Biol Lett 2(3):412-414. https://doi.org/10.1098/ rsbl.2006.0509

Bocchiaro P, Zimbardo PG, Van Lange PA (2012) To defy or not to defy: an experimental study of the dynamics of disobedience and whistle-blowing. Soc Influ 7(1):35-50. https://doi.org/10.1080/15534510.2011.648421

Brody RG, Coulter JM, Lin S (1999) The effect of national culture on whistleblowing perceptions. Teach Bus Ethics 3(4):383-398. https://doi.org/10.1023/ a:1009895700644

Brody RG, Coulter JM, Mihalek PH (1998) Whistle-blowing: a cross-cultural comparison of ethical perceptions of US and Japanese accounting students. Am Bus Rev 16(2):14-21

Burger JM (2009) Replicating Milgram: would people still obey today? Am Psychol 64(1):1-11. https://doi.org/10.1037/a0010932

Chiu RK (2003) Ethical judgment and whistleblowing intention: examining the moderating role of locus of control. J Bus Ethics 43:65-75. https://doi.org/ 10.1023/A:1022911215204

Christie PMJ, Kwon IWG, Stoeberl PA, Baumhart R (2003) A cross-cultural comparison of ethical attitudes of business managers: India, Korea and the United States. J Bus Ethics 46(3):263-287. https://doi.org/10.1023/ a: 1025501426590

Consumer Affairs Agency (CAA) (2018a) Gaibutsuho no hogoyoken ni kansuru sankojianto (Cases and regulations on the status of protection for whistleblowers). https://www.cao.go.jp/consumer/history/05/kabusoshiki/koueki/ doc/012_180418_sankou1.pdf. Accessed 20 Apr 2020

Consumer Affairs Agency (CAA) (2018b) Jigyoshato niokeru tsuhotaisei no seibinikakaru chosakekka sankojianto (Corporate whistleblowing systems: research results and cases). https://www.cao.go.jp/consumer/history/05/ kabusoshiki/koueki/doc/013_180516_sankoul.pdf. Accessed 20 Apr 2020

Consumer Affairs Agency (CAA) (2018c) Naibutsuhoseido nikansuru ninshoseido no donyunitsuite (Designation of accrediting organizations for the implementation of accreditation of whistleblowing systems). https://www.caa.go.jp/policies/policy/ consumer_system/whisleblower_protection_system/research/review_ meeting 001/pdf/review meeting 001_180501 0001.pdf. Accessed 20 Apr 2020

Darley JM, Latané B (1968) Bystander intervention in emergence: diffusion of responsibility. J Pers Soc Psychol 8(4):377-383

Dozier JB, Miceli MP (1985) Potential predictors of whistle-blowing: a prosocial behavior perspective. Acad Manag Rev 10(4):823-836. https://doi.org/ 10.5465/amr.1985.4279105

Dungan J, Waytz A, Young L (2015) The psychology of whistleblowing. Curr Opin Psychol 6:129-133. https://doi.org/10.1016/j.copsyc.2015.07.005

Dungan JA, Young L, Waytz A (2019) The power of moral concerns in predicting whistleblowing decisions. J Exp Soc Psychol 85:103848. https://doi.org/ 10.1016/j.jesp.2019.103848

Dyck A, Morse A, Zingales L (2010) Who blows the whistle on corporate fraud? J Finance 65(6):2213-2253. https://doi.org/10.3386/w12882

Fehr E, Fischbacher U (2004) Third-party punishment and social norms. Evol Hum Behav 25(2):63-87. https://doi.org/10.1016/s1090-5138(04)00005-4

Financial Reporting Council (2018) The UK Corporate Governance Code, July 2018

G20 and OECD (2015) G20/OECD Principles of Corporate Governance, 30 November 2015 
Gino F, Ayal S, Ariely D (2009) Contagion and differentiator in unethical behavior. Psychol Sci 20(3):393-398. https://doi.org/10.1111/j.1467-9280.2009.02306.x

Gino F, Ayal S, Ariely D (2013) Self-serving altruism? The lure of unethical actions that benefit others. J Econ Behav Organ 93(C):285-292. https://doi.org/ 10.1016/j.jebo.2013.04.005

Guth W, Schmittberger R, Schwarze B (1982) An experimental analysis of ultimatum bargaining. J Econ Behav Organ 3(4):367-388. https://doi.org/ 10.1016/0167-2681(82)90011-7

Harvey AH, Kirk U, Denfield GH et al. (2010) Monetary favors and their influence on neural responses and revealed preference. J Neurosci 30(28):9597-9602. https://doi.org/10.1523/jneurosci.1086-10.2010

Hashimoto J (1991) Nihonkeizai: 20-seiki shisutemu to nihon keizai (The Japanese economy: 20th-century systems and the Japanese economy). Minerva Shobo, Tokyo

Kobe Steel Inspection Committee (2018) Toshagurupu niokeru futekisetsukoi nikansuru hokokusho (Report on inappropriate actions at Kobe Steel group). 6 March 2018. https://www.kobelco.co.jp/releases/files/20180306_report.pdf. Accessed 14 Jan 2020

Kubori H (2018) Fushojino yobo to jigotaio (Prevention and handling of misconduct). 19 February 2018. https://www.jpx.co.jp/regulation/seminar/files/ 201702kubori.pdf. Accessed 14 Jan 2020

Kubori H (2019) Tahatsu suru fushojino yobo to kokaikaisha no torikumi (Efforts by public companies to prevent and respond to frequent misconduct). In: Ozaki Y, Kawashima I, Wakabayashi Y (eds) Laws on public companies and capital market. Shojihomu, Tokyo, pp. 287-322

Latané B, Darley JM (1969) Bystander "apathy". Am Sci 57(2):244-268

Licht AN (2018) Culture and law in corporate governance. In: Gordon JN, Ringe WG (eds) The Oxford handbook of corporate law and governance. Oxford University Press, Oxford, pp. 129-158

Maruyama M (1992) Chusei to hangyaku (Loyalty and rebellion). Chikuma Shobo, Tokyo

Mazar N, Aggarwal P (2011) Greasing the palm: can collectivism promote bribery? Psychol Sci 22(7):843-848. https://doi.org/10.1177/0956797611412389

Mazar N, Ariely D (2006) Dishonesty in everyday life and its policy implications. J Public Policy Mark 25(1):117-126. https://doi.org/10.1509/jppm.25.1.117

Miceli MP, Near JP, Rehg MT, Van Scotter JR (2012) Predicting employee reactions to perceived organizational wrongdoing: demoralization, justice, proactive personality, and whistle-blowing. Hum Relat 65(8):923-954. https://doi.org/10.1177/0018726712447004

Milgram S (1963) Behavioral study of obedience. J Abnorm Soc Psychol 67 (4):371-378. https://doi.org/10.1037/h0040525

Ministry of Land, Infrastructure, Transportation and Tourism (MLIT) (2015) Menshinzairyo nikansuru daisanshaiinkaihoukokusho (Report by inspection committee on materials). 29 July 2015. https://www.mlit.go.jp/common/ 001098850.pdf. Accessed 14 Jan 2020

Mitsubishi Material Inspection Committee (2018) Tokubetsu chosaiinkai saishuhokokusho (Report on inspection on inappropriate events and issues of group management). 27 March 2018. https://www.mmc.co.jp/corporate/ja/ news/press/2018/pdf/18-0328a.pdf. Accessed 14 Jan 2020

Moore DA, Tanlu L, Bazerman MH (2010) Conflict of interest and the intrusion of bias. Judgm Decis Mak 5(1):37-53

Nakane C (1967) Tateshakaino ningenkankei (Human relationships in a vertical society). Kodansha, Tokyo

Nemeth C (2018) In Defense of troublemakers: the power of dissent in life and business. Basic Books, New York

Nissan Inspection Committee (2017) Sharyoseizokojo niokeru futekisetsuna kanseikensa no jisshinitsuite chosahokokusho (Report on inspection on inappropriate product safety inspection). 17 November 2017. https://www.nissanglobal.com/PDF/20171117_report01.pdf. Accessed 14 Apr 2020

Olympus Corporation (2019) Olympus Corporation announces transformation plan. 11 January 2019. https://www.olympus-global.com/news/2019/ contents/nr01100/nr01100_00000.pdf. Accessed 20 Apr 2020

Olympus Corporation and Sony Corporation (2012) Announcement of agreements between Olympus and Sony to form business and capital alliance. 28 September 2012. https://www.sony.net/SonyInfo/News/Press/201209/12-0928E/. Accessed 20 Apr 2020

Securities and Exchange Surveillance Commission (SESC) (2019) Nissan jidosha kabushikikaisha niokeru yukashokenhoukokushoto no kyogikisai nikakaru kachokinnofumeirei nitsuite (Recommendation for administrative monetary penalty payment order for Nissan Motor Co., Ltd. for making false statements in its disclosure documents). 10 December 2019. https://www.fsa.go.jp/ sesc/news/c_2019/2019/20191210-2.html. Accessed 14 Apr 2020
Tenbrunsel AE (1998) Misrepresentation and expectations of misrepresentation in an ethical dilemma: the role of incentives and temptation. Acad Manag J 41 (3):330-339. https://doi.org/10.2307/256911

Tenbrunsel AE, Smith-Crowe K, Umphress EE (2003) Building houses on rocks: the role of the ethical infrastructure in organizations. Soc Justice Res 16 (3):285-307

Thompson L, Loewenstein G (1992) Egocentric interpretations of fairness and interpersonal conflict. Organ Behav Hum Decis Process 51(2):176-197. https://doi.org/10.1016/0749-5978(92)90010-5

Tokyo District Court (2016) Wakaichosho (Record of settlement), Cases 25114 and 33859. 18 February 2016

Tokyo Stock Exchange (TSE) (2018) Japan's corporate governance code: seeking sustainable corporate growth and increased corporate value over the mid- to long-term. https://www.jpx.co.jp/english/equities/listing/cg/tvdivq0000008jdyatt/20180601.pdf. Accessed 14 January 2020

Tokyo Stock Exchange (TSE) (2019) TSE-listed companies white paper on corporate governance 2019. https://www.jpx.co.jp/equities/listing/cg/tvdivq0000 008jb0-att/nlsgeu0000043lyw.pdf. Accessed 14 January 2020

Toray Inspection Committee (2017) Chosahokusho (Report on internal inspection). 25 December 2017. https://www.toray.co.jp/news/fiber/20171227.pdf. Accessed 14 Apr 2020

Tversky A, Kahneman D (1973) Availability: a heuristic for judging frequency and probability. Cogn Psychol 5(2):207-232. https://doi.org/10.1016/0010-0285 (73) $90033-9$

Vadera AK, Aguilera RV, Caza BB (2009) Making sense of whistle-blowing's antecedents: learning from research on identity and ethics programs. Bus Ethics Q 19(4):553-586. https://doi.org/10.5840/beq200919432

Waldenberger F (2016) In-house carriers: a core institution of the Japanese firm in need of reform. J Strateg Manag Stud 8(1):23-32

Wang S, Miyamoto S, Konno H et al. (2003) Shakaishinrigaku no kantenkaramita naibukokuhatsu (Whistle-blowing as a deterrent to organizational wrongdoing from the sociopsychological point of view). Shakaigijutsukenkyuronbunshu (Sociotechnica) 1:268-277. https://doi.org/10.3392/sociotechnica.1.268

Waytz A, Dungan J, Young L (2013) The whistleblower's dilemma and the fairness-loyalty tradeoff. J Exp Soc Psychol 49(6):1027-1033. https://doi.org/ 10.1016/j.jesp.2013.07.002

Woodford MC (2012) Kainin (Dismissal). Hayakawa Shobo, Tokyo

\section{Acknowledgements}

This work was supported by the Institute of Internal Auditors Japan (Research Grant 2018).

\section{Competing interests}

The author declares no competing interests.

\section{Additional information}

Correspondence and requests for materials should be addressed to D.A.

Reprints and permission information is available at http://www.nature.com/reprints

Publisher's note Springer Nature remains neutral with regard to jurisdictional claims in published maps and institutional affiliations.

Open Access This article is licensed under a Creative Commons Attribution 4.0 International License, which permits use, sharing, adaptation, distribution and reproduction in any medium or format, as long as you give appropriate credit to the original author(s) and the source, provide a link to the Creative Commons license, and indicate if changes were made. The images or other third party material in this article are included in the article's Creative Commons license, unless indicated otherwise in a credit line to the material. If material is not included in the article's Creative Commons license and your intended use is not permitted by statutory regulation or exceeds the permitted use, you will need to obtain permission directly from the copyright holder. To view a copy of this license, visit http://creativecommons.org/ licenses/by/4.0/

(c) The Author(s) 2020, corrected publication 2021 